\title{
Development of flow cytometric opsonophagocytosis and antibody- mediated complement deposition assays for non-typeable Haemophilus influenzae
}

\author{
Stephen R. Thomas ${ }^{1 *}$ (D) Stephanie Leung ${ }^{1}$, Katy Knox ${ }^{1}$ Tom M. A. Wilkinson², Karl J. Staples ${ }^{2}$, Pascal Lestrate ${ }^{3}$,
} Dominique Wauters ${ }^{3}$, Andrew Gorringe ${ }^{1}$ and Stephen C. Taylor ${ }^{1}$

\begin{abstract}
Background: Haemophilus influenzae is found in the nasopharynx of $80 \%$ of the human population. While colonisation with non-typeable Haemophilus influenzae (NTHi) is usually asymptomatic, it is capable of causing acute and chronic otitis media (OM) in infants, invasive disease in susceptible groups and is the leading cause of exacerbations of patients with chronic obstructive pulmonary disease (COPD).

Current methods for assessing functional antibody immunity to NTHi are limited and labour intensive. Flow cytometric assays could provide an attractive alternative to evaluate immune responses to candidate vaccines in clinical trials.

Results: We have developed a duplexed flow-cytometric uptake and oxidative burst opsonophagocytosis assay (fOPA). We have also developed a duplexed antibody-mediated complement C3b/iC3b and C5b-9 deposition assay (CDA). Antibody-mediated C3b/iC3b deposition correlated with opsonophagocytic uptake $(r=0.65)$ and with opsonophagocytic oxidative burst $(r=0.69)$. Both fOPA and CDA were reproducible, with the majority of samples giving a coefficient of variation (CV) of $<20 \%$ and overall assay CVs of $14 \%$ and $16 \%$ respectively.

Conclusions: The high-throughput flow cytometric assays developed here were successfully optimised for use with NTHi. Assays proved to be sensitive and highly reproducible for the measurement of bacterial uptake and oxidative burst opsonophagocytosis and antibody-mediated deposition of C3b/iC3b and C5b-9. These assays are useful tools for use in large scale epidemiological studies and to assist in the assessment of functional antibody induced by NTHi candidate vaccines.
\end{abstract}

Keywords: Non-typeable Haemophilus influenzae, Antibody, Opsonophagocytosis, Complement, Flow cytometry, Vaccine

\section{Background}

Haemophilus influenzae are common colonising organisms of the human nasopharynx, found in $80 \%$ of the human population [1]. The majority of colonisation is made up of unencapsulated or non-typeable $H$. influenzae (NTHi) strains [1]. Although colonisation with NTHi is usually asymptomatic, it is also capable of causing disease, accounting for approximately $20-40 \%$ of all cases of acute and recurrent acute otitis media (AOM)

\footnotetext{
* Correspondence: steve.thomas@phe.gov.uk

${ }^{1}$ Public Health England, Microbiological Services, Porton Down, Salisbury SP4 OJG, UK

Full list of author information is available at the end of the article
}

infections in young children [2-4]. More worrying is the impact of NTHi infection as a cause of exacerbations in chronic obstructive pulmonary disease (COPD) patients, with $25-80 \%$ of cases resulting in severe respiratory complications [5]. In the UK alone, 1 million people are diagnosed with COPD while a further 2 million are estimated to be undiagnosed [6]. Moreover, at any time 30\% of COPD patients are colonised with NTHi [7]. The incidence of invasive disease, such as septicaemia, pneumonia and meningitis as a result of NTHi infection, although still relatively rare, has also been observed in specific risk groups and has been increasing in prevalence over the last two decades [8]. 
Prevention of disease and concerns of the possible emergence of antibiotic resistance due to repeated and inappropriate treatment is becoming a high priority, and a vaccine to protect against NTHi disease would be of particular value [9]. The lack of a capsule has meant that the search for a vaccine has concentrated on identifying suitable outer membrane proteins [10]. To date there are a number of conserved outer membrane proteins that have been identified as possible vaccine candidates [9-11], one of which has been used as a carrier protein in GSK's 10-valent pneumococcal conjugate vaccine [12]. Studies have shown a reduction in the incidence of $\mathrm{OM}$ in children due to pneumococcal infection and also NTHi [13-15]. Previous studies have developed serum bactericidal assays (SBA) [16] or killing opsonophagocytosis assays (kOPA) [17] to measure functional antibodymediated immunity to NTHi. However, while SBA has been established as a correlate of protection for invasive disease caused by encapsulated Haemophilus influenzae type $\mathrm{b}$ (Hib) and has been used in efficacy studies for Hib vaccines [18] a reliable correlate of protection has yet to be identified for disease due to NTHi (e.g. AOM, exacerbation of COPD) [19]. A human challenge model showed that colonised individuals showed a 4-fold increase in serum levels of IgA, IgM or IgG [20]. Modest bactericidal activity has been observed against homologous NTHi strains in convalescent sera of children with a previous AOM infection [21], with further smaller studies showing bactericidal activity to the homologous strain lacking in acute sera but present in convalescent sera which appears not to induce protection from heterologous strains $[3,22,23]$. However, a large natural immunity study or vaccine efficacy study has yet to be carried out in order to establish SBA as an immune correlate of protection for NTHi disease. Both assays could result in reproducible methods that would only require minimal volumes of sera and could greatly enhance candidate vaccine testing.

Antibody-mediated deposition of C3b and C5b-9 is required for opsonophagocytosis and bactericidal activity respectively, thus analysis of the antibody-mediated deposition of these complement components could inform the analysis of immune responses to NTHi natural infection and vaccines.

\section{Materials and methods}

\section{Serum samples}

Pre-and post-vaccination serum ( $n=6$ and 7 respectively) were convenience samples that had been previously collected from healthy laboratory staff based at Public Health England (PHE), Porton Down, following a single dose of Synflorix. Vaccination had been offered to staff working in laboratories using cultures of NTHi and Streptococcus pneumoniae. All sera were collected in
$8.5 \mathrm{ml}$ serum separation tubes (BD vacutainer SST advance gold), heat-inactivated for $30 \mathrm{~min}$ at $56{ }^{\circ} \mathrm{C}$ and then stored at $4{ }^{\circ} \mathrm{C}$ for short-term storage, or $-20{ }^{\circ} \mathrm{C}$ for long-term storage. Sera raised in mice immunised with heat-killed NTHi bacteria formulated with $0.33 \%$ Alhydrogel at days 0,21 , and 28 with a terminal bleed at day 35 were used, as well as a mouse non-immune serum (NIS) obtained using Alhydrogel only as a negative control. Sera $(n=35)$ were obtained from subjects with stable mild and moderate COPD (provided by University of Southampton Faculty of Medicine).

\section{Complement source}

IgG-depleted human plasma from healthy volunteers was prepared as described by Brookes et al. [24] and used for all assays. The complete removal of IgG from the preparation was confirmed by IgG ELISA (Bethyl Laboratories), performed according to manufacturer's instructions and showed values below the level of detection.

\section{Bacteria}

NTHi strains 3655, 3224A and MPJ003 (supplied by GSK) were grown on chocolate agar, supplemented with PolyVitex (Biomerieux SA, France), overnight at $37^{\circ} \mathrm{C}$ in $5 \% \mathrm{CO}_{2}$. The growth from each plate was re-suspended in $2.5 \mathrm{ml}$ brain heart infusion broth supplemented with hemin and nicotinamide adenine dinucleotide (NAD) (sBHI). The $\mathrm{OD}_{620 \mathrm{~nm}}$ was determined for the $2.5 \mathrm{ml}$ culture, which was then used to calculate the volume of inoculum required to give a starting $\mathrm{OD}_{620 \mathrm{~nm}}$ of 0.08 in sBHI. Cultures were incubated at $37{ }^{\circ} \mathrm{C}$ with shaking at $180 \mathrm{rpm}$ until an $\mathrm{OD}_{620 \mathrm{~nm}}$ of $0.35-0.45$ was achieved (mid-log phase). For use in all other assays, other than the flow cytometric OP assay, bacteria were then washed in $1 \mathrm{ml}$ phosphate-buffered saline (PBS) to create a working stock. For use in the flow cytometric OP assay bacteria were fluorescently labelled with a $1 \mathrm{mM}$ stock solution of CellTrace violet cell proliferation kit (Life technologies) prepared by adding dimethyl sulphoxide (DMSO) to the appropriate number of vials to give a final working concentration of $100 \mu \mathrm{M}$. Bacteria were incubated for $20 \mathrm{~min}$ at $37{ }^{\circ} \mathrm{C}$ with shaking at $180 \mathrm{rpm}$ and protected from light. Bacteria were washed once in PBS before re-suspending the pellets in $1 \mathrm{ml}$ PBS. The bacterial concentration was calculated assuming that an $\mathrm{OD}_{620}$ of 1.0 corresponds to $4.0 \times 10^{9} \mathrm{ml}^{-1}$ colony forming units.

\section{Cell line growth and differentiation}

HL-60 cells (human promyelocytic leukemia cells; CCL240; American Type Culture Collection, Rockville, USA) were maintained and differentiated into granulocytes as described by Humphries et al. [25]. 


\section{Duplexed uptake and oxidative burst flow-cytometric opsonophagocytosis assay (fOPA)}

CellTrace violet-labelled bacteria were prepared at $5.0 \times$ $10^{9} \mathrm{ml}^{-1}$ in blocking buffer (OPA-BB) (2\% skimmed milk powder in $\mathrm{HBSS}$ containing $1.2 \mathrm{mM} \mathrm{CaCl}_{2} \cdot 2 \mathrm{H}_{2} \mathrm{O}$ and $1 \mathrm{mM} \mathrm{MgSO}_{4} \cdot 7 \mathrm{H}_{2} \mathrm{O}$ ). $5 \mu \mathrm{l}$ of heat inactivated serum was added to appropriate wells of a standard U-bottom 96-well plate. $15 \mu \mathrm{l}$ of OPA-BB was added to wells containing sera, or an appropriate amount to control wells to give a final volume of $40 \mu \mathrm{l}$ prior to addition of HL-60 cells. $10 \mu$ l bacteria were added to every well except the HL-60 cells-only control. Samples were incubated for $15 \mathrm{~min}$ at $37^{\circ} \mathrm{C}$ with shaking at $900 \mathrm{rpm} .10 \mu \mathrm{l}$ of 1:10 diluted IgG-depleted human plasma (diluted in OPA-BB) was added to appropriate wells, followed by a further incubation for $7.5 \mathrm{~min}$ at $37{ }^{\circ} \mathrm{C}$ with shaking at $900 \mathrm{rpm}$. Differentiated HL-60 cells at $2.5 \times 10^{7} \mathrm{ml}^{-1}$ were prepared in OPA-BB and $25 \mu$ l added to all wells along with a further $25 \mu \mathrm{l}$ Dihydrorhodamine 123 (25 $\mu \mathrm{g} / \mathrm{ml}$ DHR 123 - Life Technologies), and incubated for $15 \mathrm{~min}$ at $37^{\circ} \mathrm{C}$ with shaking at $900 \mathrm{rpm}$. Following this, microtitre plates were immediately placed on ice and samples fixed with $80 \mu \mathrm{l} 1 \%$ formaldehyde in Dulbecco's PBS $+0.02 \%(w / v)$ EDTA and incubated for $30 \mathrm{~min}$ at RT in the dark before analysis by flow cytometry. All tests were performed in duplicate and the following controls were used: HL-60 cells only (unstained), HL-60 cells only (DHR-123 stained), HL-60 cells plus bacteria and finally HL-60 cells plus bacteria and complement. Two wells containing $10 \mu \mathrm{l}$ phagotest (Glycotope Biotechnology), with $20 \mu \mathrm{l}$ buffer, $10 \mu \mathrm{l} 5 \%$ complement and $50 \mu \mathrm{l}$ HL-60 cells were also included. The phagotest (Escherichia coli) is pre-stained with a FITC stain and pre-opsonised therefore no stain or serum was added.

\section{Flow-cytometric complement C3b/iC3b and C5b-9 deposition assay (CDA)}

$5 \mu \mathrm{l}$ heat-inactivated test sera were added to the relevant wells of a standard U-bottom 96-well microtitre plate, followed by $2 \mu \mathrm{l}$ IgG-depleted human plasma and $93 \mu \mathrm{l}$ bacteria at an $\mathrm{OD}_{620 \mathrm{~nm}} 0.1$ in CDA-BB (2\% bovine serum albumin in PBS $w / v)$. The plate was then incubated at $37{ }^{\circ} \mathrm{C}$ for $45 \mathrm{~min}$ with shaking at $900 \mathrm{rpm}$. Following incubation, the plate was centrifuged at $3060 \mathrm{~g}$ for $5 \mathrm{~min}$ and washed using CDA-BB. The resulting pellet was re-suspended in $200 \mu$ l of conjugate (FITC-conjugated rabbit polyclonal antibody to human C3c (Abcam, UK) and murine sC5b-9 neoantigen monoclonal antibody (Quidel, US, clone 056B-75.2.3.10) custom conjugated to Alexafluor 647 (Life Technologies Ltd., UK)) which were used at a 1:500 and 1:4000 dilution respectively. The plate was then incubated for a further $20 \mathrm{~min}$ at $4{ }^{\circ} \mathrm{C}$. Following this the plate was centrifuged at $3060 \mathrm{~g}$ for $5 \mathrm{~min}$ and washed with CDA-BB; this wash step was repeated twice more before the pellet was finally re-suspended with $1 \%$ formaldehyde in PBS and incubated for $30 \mathrm{~min}$ at RT. The completed assay was analysed by flow cytometry on the same day. All tests were performed in duplicate and the following controls were used in each assay: bacteria only, bacteria and detection antibody only and finally bacteria with complement and conjugate only.

\section{Flow cytometric analyses}

Samples were analysed using a Beckman Coulter Cyan flow cytometer equipped with a Cytek 96-well microtitre plate sampler. Protocols were established to analyse profiles of events identified on the cytometer by the forward scatter (FS), measuring the size of the cell, and side scatter (SS), measuring the granularity and internal structural complexity. For each sample, approximately 10,000 individual events were analysed for fluorescence and a horizontal gate was drawn to include $10 \%$ of the antibody-independent control sample population (bacteria plus IgG-depleted human plasma plus conjugate for CDA and HL-60 cells plus bacteria plus IgGdepleted plasma for fOPA). A mean fluorescence index (MFI) was calculated for each sample, which involved the multiplication of the percent of events moving into the horizontal gate (\%-gated), by the average fluorescence of that population (X-mean). The final result for each test was expressed as the average MFI (average FI taken for duplicate test samples) of the test serum sample minus the average MFI of the antibody-independent control sample population (MFI-control).

\section{Results}

A fOPA was developed from protocols previously described for Neisseria meningitidis by Findlow et al. 2006 and Humphries et al. 2015 [25, 26]. Early results showed either low or variable levels of opsonophagocytosis, with high antibody-independent fluorescence masking antibodymediated opsonophagocytosis, therefore optimisation was required.

The opsonophagocytic uptake protocol used by Findlow for $N$. meningitidis [26] had two $7.5 \mathrm{~min}$ incubation steps, the first following addition of serum, bacteria and complement and the second following addition of differentiated HL-60 cells. However when this approach was used with NTHi the results showed high levels of antibodyindependent fluorescence and therefore very little distinction was observed for antibody-mediated uptake of bacteria (Additional file 1: Figure S1). The assay was therefore performed in 3 steps (30 min with serum plus bacteria, $15 \mathrm{~min}$ following addition of complement and finally $30 \mathrm{~min}$ following addition of differentiated HL-60 cells) [25]. Using this protocol increased antibody-mediated fluorescence 
compared to the no antibody control values was observed (Additional file 2: Figure S2A). These times were reduced to $15 \mathrm{~min}, 7.5 \mathrm{~min}$ and $15 \mathrm{~min}$ when duplexing the fOPA to include measurement of oxidative burst with no loss of assay sensitivity (Additional file 2: Figure S2B).

Two fluorochromes were evaluated for staining of the bacteria to investigate phagocytic uptake. Live NTHi were incubated with BCECF, AM $\left(2^{\prime}, 7^{\prime}\right.$-bis-(2-carboxyethy1)-5-(and-6)-carboxyfluorescein acetoxymethyl ester) (described by Humphries et al.) [25] or CellTrace ${ }^{\mathrm{Tw}}$ violet cell proliferation dye (CTV). Unexpectedly, BCECF staining of NTHi appeared to inhibit uptake by HL-60 cells and was therefore unsuitable for the assay (Additional file 3: Figure S3). However, the same assay carried out with CTVstained NTHi showed a serial dilution of OPA activity mediated by antibody in post-Synflorix human serum (Fig. 1). While the mouse NIS and mouse anti-3655 sera were initially used to provide a negative and positive control, the dilution data also showed that there was a clear increase following administration of the NTHi whole cell vaccine. Thus CTV-stained NTHi were used to determine uptake by HL-60 cells and the assay serum concentration was established.

In addition to using fluorescently-labelled bacteria to measure opsonophagocytic uptake, a fluorescent stain to detect oxidative burst was also investigated. Dihydrorhodamine 123 (DHR-123) has been used in a number of previously described opsonophagocytosis assays $[27,28]$. These experiments were performed using HL-60 cells prestimulated with IFNy, as this has previously been shown to improve oxidative burst [29]. However, the omission of IFNy resulted in considerably higher MFI-control values when compared to those with pre-stimulation (Fig. 2). Initially oxidative burst by differentiated HL-60 cells was evaluated independently of uptake. Oxidative burst by the HL-60 cells in the presence of NTHi and human serum was considerably lower than seen previously with $N$. meningitidis [25] (Fig. 2: Black bars).
Parallel measurement of both uptake of bacteria and oxidative burst was then assessed using a panel of 17 sera. Correlations between duplexed uptake and oxidative burst fluorescence for strains 3655, 3224A and MPJ003 were $0.85,0.89$ and 0.97 respectively $(p=<$ 0.001). Additional file 4: Figure S4 shows the relationship between opsonophagocytic uptake and oxidative burst for individual sera with NTHi, strain 3224A (Additional file 4: Figure S4). Correlations between the duplexed assay and a single parameter OPA uptake assay for strains 3655, 3224A and MPJ003 were 0.74, 0.79 and 0.94 respectively $(p=<0.001)$. Between the duplexed assay and single parameter OPA oxidative burst assay, correlations for strains $3655,3224 \mathrm{~A}$ and MPJ003 were $0.67(p=0.003), 0.71(p=$ $0.002)$ and $0.97(p=<0.001)$ respectively. All correlations are expressed as $\mathrm{r}$ values by Pearson correlation coefficient. Inter-assay precision of the duplexed assay was determined by one operator over 3 days for strains 3224A and 3655, and over 4 days for strain MPJ003. Low CV values were observed for all assays with the majority of samples giving a CV of $<20 \%$ for uptake and oxidative burst (Table 1).

The complement deposition assay (CDA) was optimised for use with NTHi by adjusting the concentration of IgG-depleted plasma and the incubation times with initial conditions based on those used by Martino et al. [30] and by Ercoli et al. [16]. The effect of $2 \%, 5 \%$ and $25 \%(v / v)$ IgG-depleted plasma with incubation times of 20 and $45 \mathrm{~min}$ was investigated. The mean fluorescence index minus the antibody-independent control (MFI-control) values demonstrated optimum assay conditions of $2 \%$ IgG-depleted plasma with an incubation time of $45 \mathrm{~min}$. MFI-control values for 20 min incubation were low while $45 \mathrm{~min}$ incubation resulted in greater $\mathrm{C} 3 \mathrm{~b} / \mathrm{iC} 3 \mathrm{~b}$ and C5b-9 binding with good differentiation between the pre and post Synflorix test sera $(p=<0.001)$ (Fig. 3). The use of $25 \%$ complement in the assay resulted in antibodyindependent fluorescent peaks comparable to those

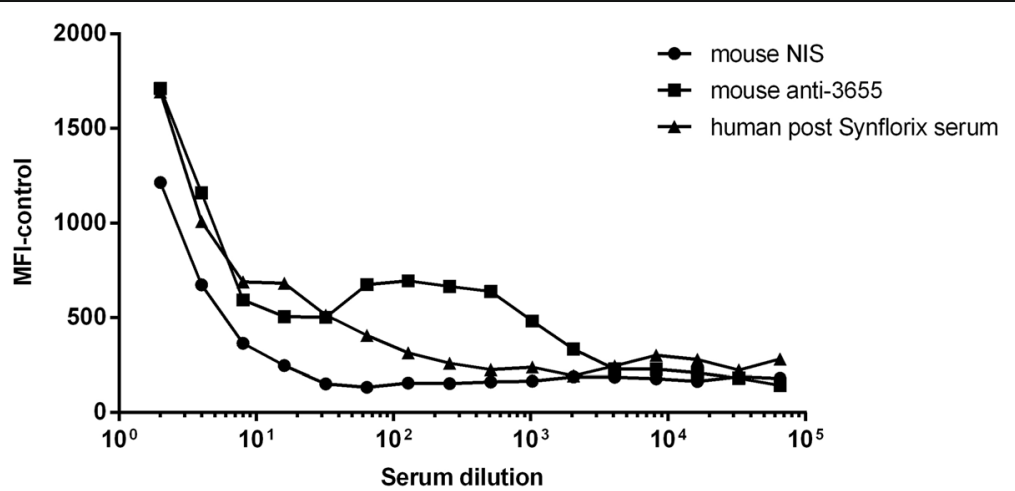

Fig. 1 Selection of a fluorescent dye to measure bacterial uptake (fOPA). CellTrace violet-labelled NTHi strain 3655 was incubated with lgG-depleted plasma, differentiated HL60 cells and dilutions of mouse non-immune (circles), mouse anti-3655 whole bacteria (squares) or human post Synflorix (triangles) serum. Each point is the mean of duplicate samples 


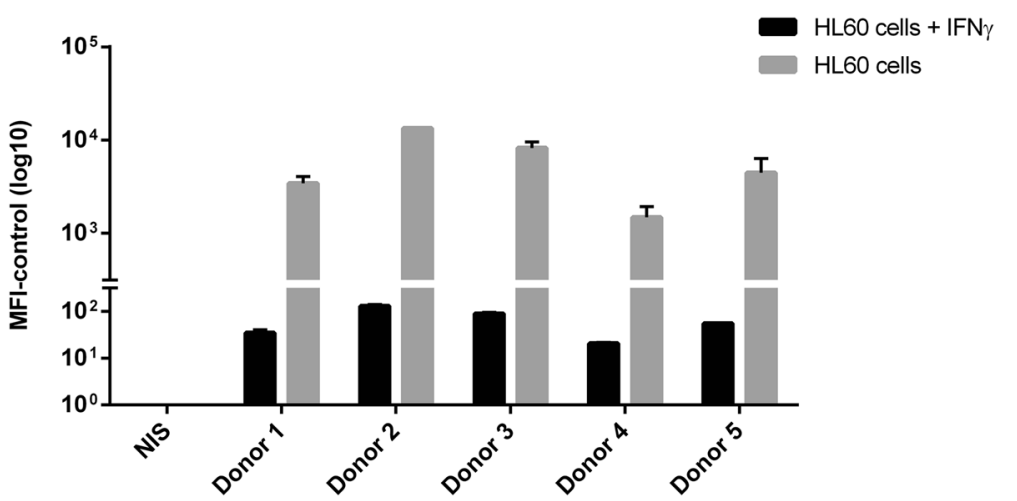

Fig. 2 Assessing the effects of pre-treatment of HL60 cells with IFNy on oxidative burst. NTHi strain 3224A was incubated with differentiated HL60 cells in the presence or absence of IFNy and either mouse non-immune serum (NIS) or human post Synflorix sera. Error bars represent the standard deviation of duplicate samples

obtained in the presence of antibody. C3b/iC3b deposition with $2 \%$ complement showed clear differentiation between values obtained with pre and post sera $(p=0.0016)$ (Fig. 4). Although antibody-mediated C5b-9 deposition was observed for the pre and post Synflorix sera with 25\% complement, there was no significant difference between the samples, while using $2 \%$ complement gave a significant difference $(p=<0.001)$ (Fig. 4). Overlay plots of the relative fluorescence intensity (RFI) for anti-C3c (measuring $\mathrm{C} 3 \mathrm{~b} / \mathrm{iC} 3 \mathrm{~b}$ deposition) and anti-C5b-9 confirmed the effect of the increased fluorescence peak shift at $45 \mathrm{~min}$ compared to $20 \mathrm{~min}$ with the antibody-independent complement binding with 25\% IgG-depleted plasma (Fig. 5).

Once optimal conditions had been established, intraassay, inter-assay and inter-operator precision of the CDA were determined for the three NTHi strains 3655, 3224A and MPJ003 using 14 human sera. The interoperator precision was performed by three operators on one day; the intra-assay precision was performed by one operator on the same day three times and the inter-assay precision was performed by one operator over three days. Low coefficient of variance $(\mathrm{CV})$ values for all assays were obtained with the majority of samples giving a CV of $<20 \%$ for C3b/iC3b deposition (Table 2) and C5b-9 deposition (Table 3).

A correlation between $\mathrm{C} 3 \mathrm{~b} / \mathrm{iC} 3 \mathrm{~b}$ deposition and OPA uptake or OPA oxidative burst was performed using a panel of 13 human sera (convenience samples previously

Table 1 OPA-uptake and OPA- oxidative burst inter-assay variability for strains 3655, 3224A and MPJ003 (17 sera per strain in triplicate, $n=153$ )

\begin{tabular}{|c|c|c|c|c|c|}
\hline \multirow[t]{2}{*}{ Assay } & \multicolumn{4}{|c|}{ Sera with defined CV } & \multirow{2}{*}{$\begin{array}{l}\text { Mean CV } \\
( \pm \text { SEM })\end{array}$} \\
\hline & $<20 \%$ & $<35 \%$ & $<40 \%$ & $>40 \%$ & \\
\hline OPA - uptake & 42 & 8 & 1 & 0 & $13.20(1.10)$ \\
\hline OPA - oxidative burst & 40 & 8 & 2 & 1 & $14.63(1.19)$ \\
\hline
\end{tabular}

collected from healthy laboratory staff) and produced values of $0.69(p=0.0089)$ and $0.65(p=0.0131)$ by Pearson correlation coefficient, both of which were significant. It was also observed that serum samples that had the highest fOPA also had the highest C3b/iC3b deposition.

Interestingly, during assay development for both flow cytometric assays, differences were observed between NTHi strains for duplexed OPA uptake and oxidative burst and for deposition of $\mathrm{C} 3 \mathrm{~b} / \mathrm{iC} 3 \mathrm{~b}$ and $\mathrm{C} 5 \mathrm{~b}-9$ using a panel of human sera from subjects with stable mild or moderate COPD (Fig. 6). Data for C3b/iC3b binding showed no significant difference between strains 3655 and $3224 \mathrm{~A}$, however there was a significant difference in deposition between 3655 and 3224A compared with MPJ003 $(p=<0.0001)$. Significant differences were observed between all strains for C5b-9 deposition ( $p=<$ 0.0001). The correlations between $\mathrm{C} 3 \mathrm{~b} / \mathrm{iC} 3 \mathrm{~b}$ and C5b-9 for strains $3655,3224 \mathrm{~A}$ and MPJ003 were $0.38(p=$ $0.025), 0.24(p=0.163)$ and $0.16(p=0.372)$ respectively by Pearson correlation coefficient. There appeared to be no strong relationship between those sera that had high deposition of $\mathrm{C} 3 \mathrm{~b} / \mathrm{iC} 3 \mathrm{~b}$ and those that had high levels of C5b-9 deposition. As with $\mathrm{C} 3 \mathrm{~b} / \mathrm{iC} 3 \mathrm{~b}$, OPA oxidative burst showed significant differences between 3655 and 3224A compared with MPJ003, but only between 3655 and MPJ003 with OPA uptake.

\section{Discussion}

The development of OP assays for unencapsulated Gram negative pathogens is difficult, as killing assays will measure a combination of antibody and complementmediated killing and killing by the phagocytic cells. Although previous studies have shown that the bactericidal activity can be blocked by the addition of antibodies against late complement components [29, 31, 32]. The use of flow cytometry to measure uptake and oxidative burst by phagocytic cells has already been used for $N$. 


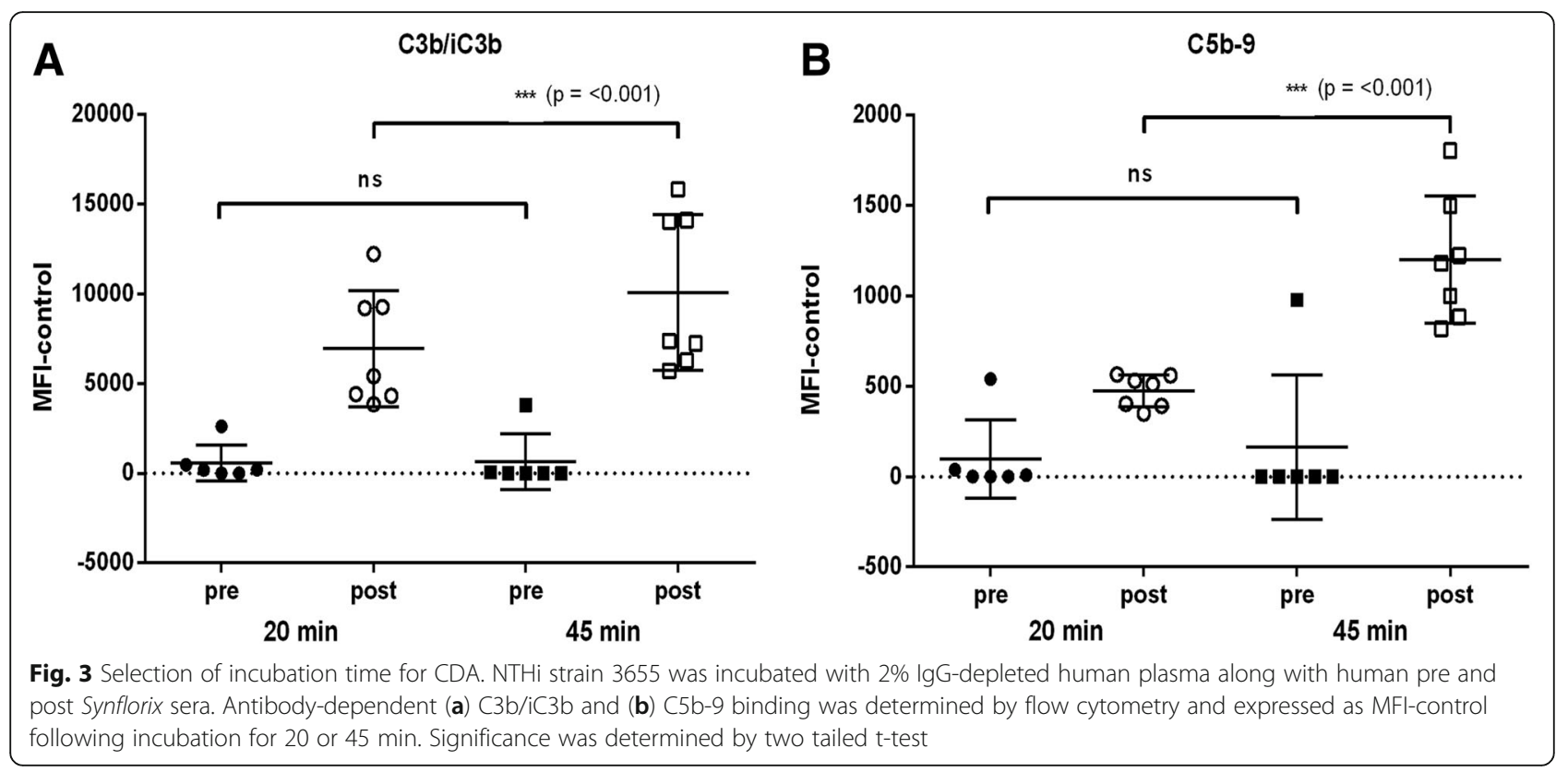

meningitidis [25, 26]. However, for NTHi we changed several parameters from the method previously described by Findlow et al. [26]. The addition of a separate incubation step for complement binding to bacteria previously incubated with antibody [25] proved to be highly effective at increasing MFI-control values, as the pre-opsonisation step allowed increased antibody binding and opsonophagocytic uptake by HL-60 cells. We initially used IFNY as this has previously been shown to prime cells to be more responsive to bacterial uptake or promote an oxidative burst response [33, 34]. However, for the NTHi fOPA, MFI-control values were considerably higher without
IFNY pre-treatment of HL-60 cells. BCECF-AM had been used successfully for the N. meningitidis OPA [25] but its use with NTHi appeared to inhibit opsonisation. As a result, CellTrace violet was investigated as an alternative. This stain enters cells by diffusion through the plasma membrane and the non-fluorescent molecule is cleaved by cell esterases to produce a fluorescent molecule that is then able to covalently bind to amine groups on intracellular proteins. CellTrace violet staining proved to be very stable and it allowed the uptake OPA to be duplexed with the measurement of DHR-123 oxidative burst fluorescence. Inter-assay precision of the duplexed assay showed
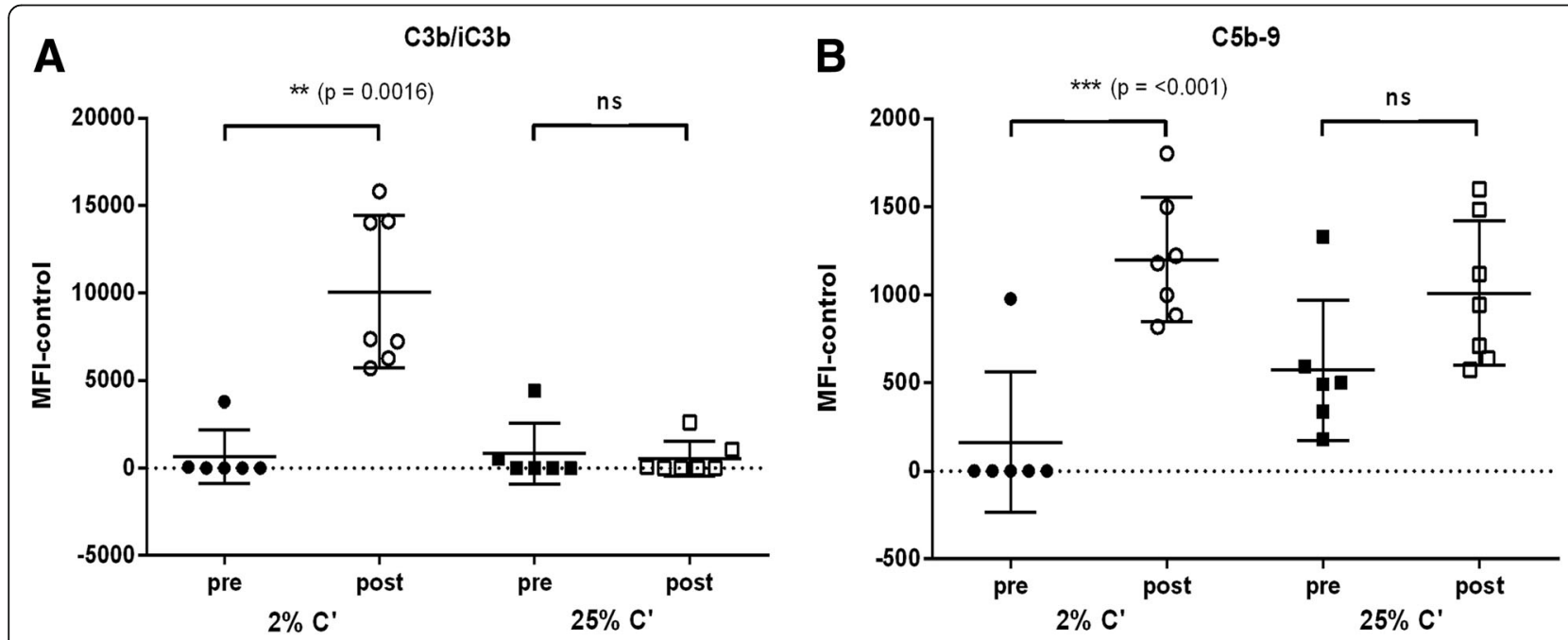

Fig. 4 Selection of complement concentration for CDA. NTHi strain 3655 was incubated for 45 min with 2\% or 25\% lgG-depleted plasma in the presence of human pre and post human Synflorix sera. Antibody-dependent (a) C3b/iC3b and (b) C5b-9 binding was determined by flow cytometry. Significance values were determined by two tailed t-test 


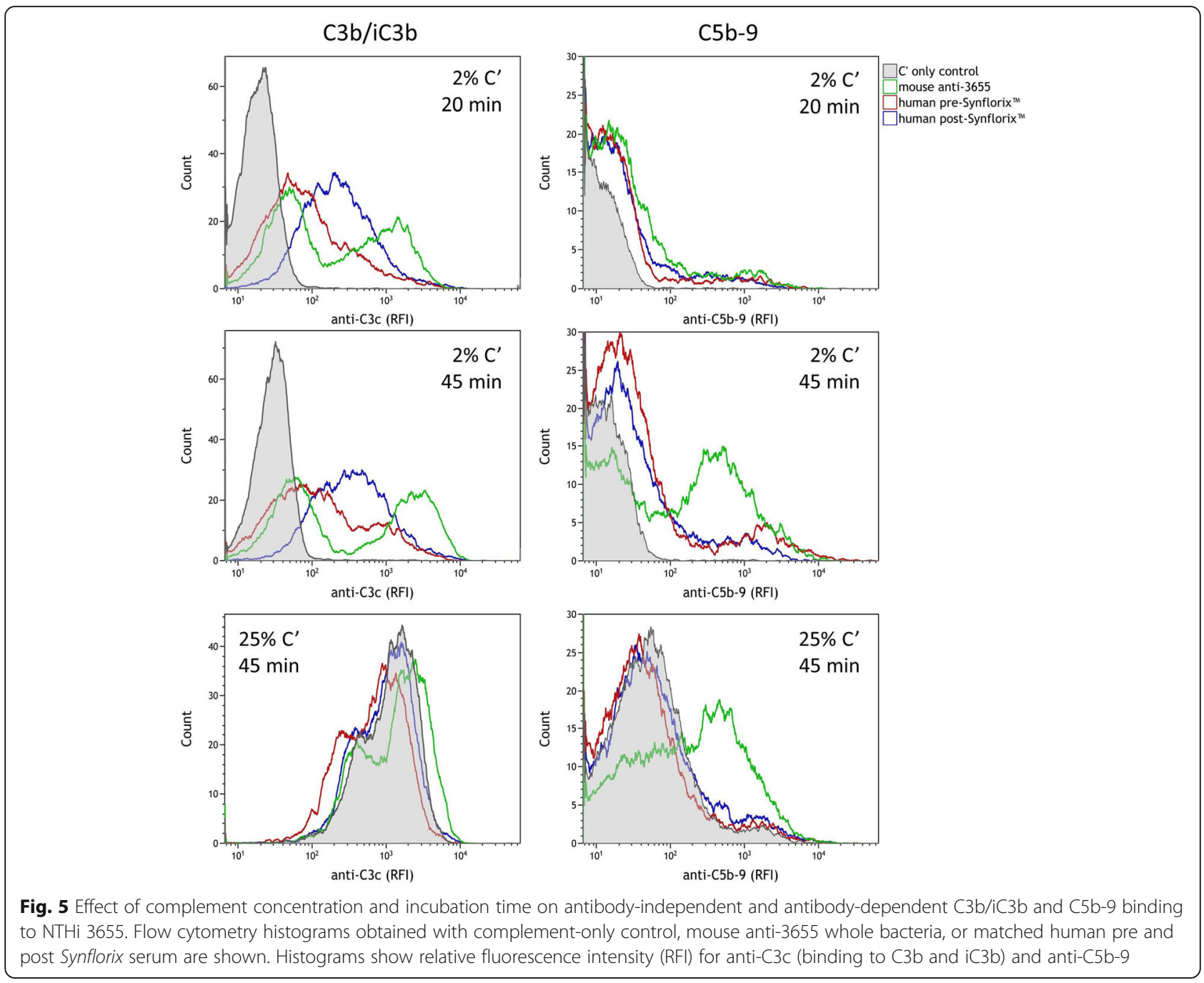

reproducible results, with the majority of samples giving a $\mathrm{CV}<20 \%$.

High levels of complement deposition were observed in the absence of antibody using CDA conditions optimised for $N$. meningitidis, [30]. Thus, for unencapsulated NTHi, optimisation was required to distinguish antibody-

Table 2 C3b/iC3b assay variability for strains 3655, 3224A and MPJ003 (14 sera per strain in triplicate, $n=126$ )

\begin{tabular}{|c|c|c|c|c|c|c|}
\hline & \multirow[t]{2}{*}{ Description } & \multicolumn{4}{|c|}{ Sera with defined CV } & \multirow{2}{*}{$\begin{array}{l}\text { Mean CV } \\
( \pm \text { SEM })\end{array}$} \\
\hline & & $<20 \%$ & $<35 \%$ & $<40 \%$ & $>40 \%$ & \\
\hline $\begin{array}{l}\text { Intra-assay } \\
\text { variability } \\
n=126\end{array}$ & $\begin{array}{l}3 \text { plates, } \\
1 \text { operator, } \\
1 \text { day }\end{array}$ & 34 & 4 & 1 & 3 & $13.09(2.27)$ \\
\hline $\begin{array}{l}\text { Inter-assay } \\
\text { variability } \\
n=126\end{array}$ & $\begin{array}{l}1 \text { plate, } \\
1 \text { operator, } \\
3 \text { days }\end{array}$ & 33 & 7 & 2 & 0 & $11.40(1.55)$ \\
\hline $\begin{array}{l}\text { Inter-operator } \\
\text { variability } \\
n=126\end{array}$ & $\begin{array}{l}1 \text { plate, } \\
3 \text { operators, } \\
1 \text { day }\end{array}$ & 26 & 6 & 3 & 7 & $21.47(2.67)$ \\
\hline
\end{tabular}

dependent from antibody-independent complement binding. To determine antibody-dependent complement deposition, we increased the incubation time from 20 to $45 \mathrm{~min}$, and reduced the complement concentration from 25 to $2 \%$. Although 5\% complement, as used by Martino et al. [30] was investigated (data not shown), similar results to those

Table 3 C5b-9 assay variability for strains 3655, 3224A and MPJ003 (14 sera per strain in triplicate, $n=126$ )

\begin{tabular}{|c|c|c|c|c|c|c|}
\hline & \multirow[t]{2}{*}{ Description } & \multicolumn{4}{|c|}{ Sera with defined CV } & \multirow{2}{*}{$\begin{array}{l}\text { Mean CV } \\
( \pm \text { SEM })\end{array}$} \\
\hline & & $<20 \%$ & $<35 \%$ & $<40 \%$ & $>40 \%$ & \\
\hline $\begin{array}{l}\text { Intra-assay } \\
\text { variability } \\
n=126\end{array}$ & $\begin{array}{l}3 \text { plates, } \\
1 \text { operator, } \\
1 \text { day }\end{array}$ & 37 & 3 & 0 & 2 & $\begin{array}{l}12.69 \\
(1.84)\end{array}$ \\
\hline $\begin{array}{l}\text { Inter-assay } \\
\text { variability } \\
n=126\end{array}$ & $\begin{array}{l}1 \text { plate, } \\
1 \text { operator, } \\
3 \text { days }\end{array}$ & 30 & 9 & 1 & 2 & $\begin{array}{l}15.87 \\
(1.71)\end{array}$ \\
\hline $\begin{array}{l}\text { Inter-operator } \\
\text { variability } \\
n=126\end{array}$ & $\begin{array}{l}1 \text { plate, } \\
3 \text { operators, } \\
1 \text { day }\end{array}$ & 26 & 11 & 0 & 5 & $\begin{array}{l}20.27 \\
(2.60)\end{array}$ \\
\hline
\end{tabular}


obtained with $25 \%$ were observed. This could be because a key component of the alternative pathway, factor D, is still present in sufficient quantities to give high antibodyindependent complement deposition [35]. Therefore the use of this concentration was excluded from consideration with NTHi. Measurement of intra-assay, inter-assay and inter-operator variability resulted in low coefficient of variance (CV) values for all individual test samples and all three NTHi strains, with the majority of samples giving a CV of $<20 \%$. Overall, the antibody-mediated complement deposition assay demonstrated good precision with a total assay CV of $16 \%$.

The protein $\mathrm{D}$ used for polysaccharide conjugation in Synflorix was not derived from any of the NTHi strains used in this study, therefore antibody rises observed between pre and post Synflorix vaccination sera are as a result of cross-reactive vaccine-derived anti-protein $\mathrm{D}$ antibodies. In addition, throughout the development of these assays it was noted that all three strains of NTHi varied greatly in OPA uptake and oxidative burst as well as the antibodymediated deposition of $\mathrm{C} 3 \mathrm{~b} / \mathrm{iC} 3 \mathrm{~b}$ and $\mathrm{C} 5 \mathrm{~b}-9$, suggesting varying degrees of susceptibility to complement-mediated killing in-vivo, dependent on strain. Variation in serum resistance of NTHi strains has also been observed by Hallström et al. who compared isolates from patients with NTHi invasive disease with isolates taken from patients with NTHi associated upper respiratory tract infection [36]. Greater complement resistance has also been observed in isolates obtained from the middle ear with a modification of lipooligosaccharide (LOS) involved [37]. LOS modification has also been shown to be important for complement resistance of a nasopharyngeal isolate [38].

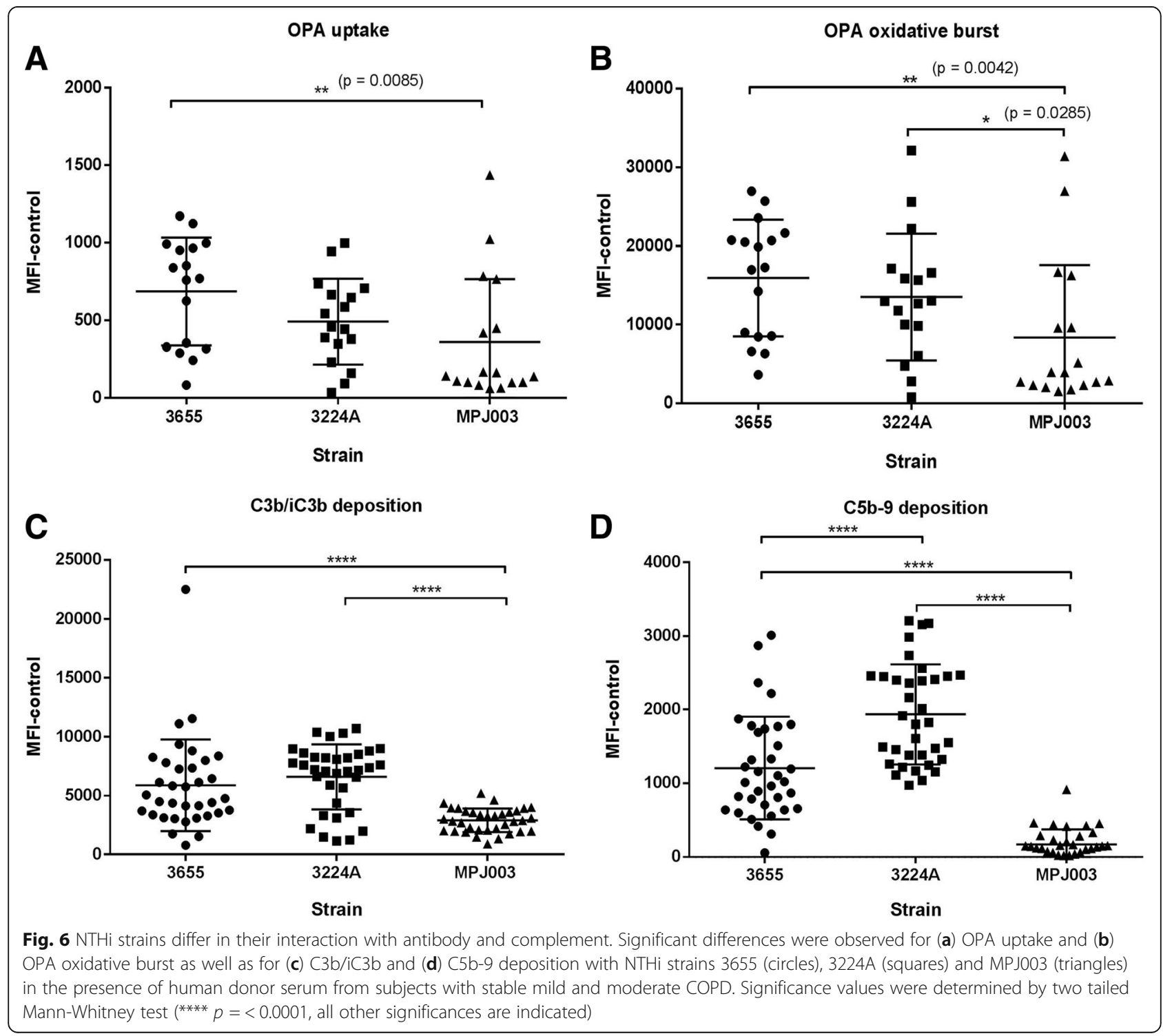


An important factor for development of both assays was the use of large scale (approximately $300 \mathrm{ml}$ batches) human IgG-depleted plasma as the exogenous complement source. To date the functional immunological assays developed for use with NTHi, such as the SBA [16] or opsonophagocytic killing assay [17] have used other mammalian sources, such as baby rabbit, or have been prepared from individual human volunteers. The use of a large scale preparation from pooled plasma means that the variability between assays is reduced, while the use of a human source of complement will allow species-specific complement interactions to be studied. For example the P5 outer membrane protein on NTHi, has been shown to specifically bind the human complement regulatory protein factor $\mathrm{H}$ [39]. The specificity of P5 for human factor $\mathrm{H}$ could therefore result in overestimation of antibody function if other mammalian sources of complement were used, in a similar manner to that observed with meningococcal antibody and complement-dependent assays [40].

Assays that have been developed to date, including the SBA [16], require considerable resources for studies involving large numbers of samples as there is a limit to the number of samples that operators can process in a day. However the fOPA has been developed using a 96-well microtitre format and a single serum dilution, meaning a single operator can process in excess of 300 samples per day. The second factor to consider with other functional assays is the possible requirement in clinical trials for multiple tests (for example with different target strains) and therefore a need for large volumes of sera, for example the SBA can use $50-100 \mu \mathrm{l}$ of serum per test when performed in duplicate $[16,41]$. This is an important factor when considering clinical trials in infants where volumes of blood samples need to be kept as small as possible. An obvious advantage of the SBA is the ability to quantify post vaccination antibody rises. However, a similar quantification could also be achieved for the flow cytometric assays with the use of commercially available secondary antibody quantification beads. As mentioned, while SBA has been used in efficacy studies for Hib vaccines and shown to be a correlate of protection for invasive disease caused by Hib [18], an immune correlate of protection against disease due to NTHi has yet to be demonstrated [19]. In addition, previous studies have shown that bactericidal activity toward heterologous strains of NTHi is poor at best [3, 22, 23 ] and there is diversity between the methods used to measure bactericidal activity in these studies. These contributing factors have meant that this study has not correlated SBA to the flow cytometric assays developed here, but should be considered in future studies. Development of a fOPA could increase the capability of vaccine assessment by measuring both bacterial uptake and oxidative burst functional antibody activity against NTHi. A flowcytometry based CDA to measure binding of complement components C3b (and its inactive form iC3b) and C5b-9 could provide a surrogate for the measurement of opsonophagocytosis and bactericidal activity respectively. The strong correlation between the fOPA results and antibodymediated complement deposition shows that the complement deposition assay could be used for large scale screening of functional antibody activity against a panel of strains, for example those that represent the spectrum of complement sensitivity seen in NTHi strains. The CDA does not require the culture and differentiation of HL-60 cells and can also be performed with $5 \mu \mathrm{L}$ of serum per test. This assay provides information on two key complement processes with $\mathrm{C} 3$ opsonising the bacteria and C5b-9 indicating membrane attack complex formation. The CDA also has a greater ability to differentiate antibody function against different strains making this a simple and useful tool for evaluation of anti-NTHi antibodies. Going forward, larger panels of vaccinee sera will be required (when accessible) to determine the specificity and utility of these assays for measuring vaccine-induced immunity to NTHi and the correlation with bactericidal activity should be assessed when suitable assays are available.

\section{Conclusions}

In the absence of a recognised immunological correlate of protection for NTHi disease we have successfully developed and optimised two high-throughput flow cytometric assays which require very low volumes of serum. Both assays proved to be sensitive for the measurement of both opsonophagocytic bacterial uptake and oxidative burst using the duplexed fOPA or antibody-mediated deposition of the complement components $\mathrm{C} 3 \mathrm{~b}$ (including $\mathrm{iC} 3 \mathrm{~b}$ ) and C5b-9. Both assays were shown to be highly reproducible.

NTHi is the leading cause of life threatening exacerbations of patients suffering with COPD and a key contributor to lifelong hearing complications in young children in the UK and worldwide. While a vaccine has shown efficacy against NTHi-associated AOM in children in some studies, no vaccine is currently available to prevent COPD exacerbations in adults. The flow cytometric assays developed here can contribute to an "immunological toolbox" to assist in functional immune assessment of future candidate vaccines from pre-clinical assessment, through to clinical trials and post-licensure surveillance.

\section{Additional files}

Additional file 1: Figure S1. Initial measurement of opsonophagocytosis Opsonophagocytic uptake was performed using a method previously optimised for $N$. meningitidis. High complement only backgrounds resulted in very little antibody-mediated uptake of bacteria being observed. (JPG $156 \mathrm{~kb}$ )

Additional file 2: Figure S2. Optimisation of fOPA incubation times Incubation of bacteria, serum, IgG-depleted plasma and HL-60 cells was 
changed from 2 steps to 3 steps (A). Times were subsequently reduced (B). (JPG $206 \mathrm{~kb}$ )

Additional file 3: Figure S3. Selection of a fluorescent dye to measure bacterial uptake. The use of BCECF to fluorescently label NTHi showed inhibition of uptake by HL-60 cells when incubated with serially diluted human serum and lgG-depleted plasma. The $Y$ axis is expressed as Average MFI as subtracting the antibody-independent control resulted in negative values for binding. Each point is the mean of duplicate samples. (JPG $246 \mathrm{~kb}$ )

Additional file 4: Figure S4. Relationship between opsonophagocytic uptake and oxidative burst for individual sera with NTHi, strain 3224A. Each point is the mean of duplicate samples. (JPG $484 \mathrm{~kb}$ )

\section{Abbreviations}

AOM: Acute otitis media; BCECF-AM: 2',7'-Bis(2-carboxyethyl)-5(6)carboxyfluorescein acetoxymethyl ester; CDA: Complement deposition assay; CDA-BB: Complement deposition assay blocking buffer; COPD: Chronic obstructive pulmonary disease; CTV: CellTrace violet; CV: Coefficient of variation; DHR 123: Dihydrorhodamine 123; DMSO: Dimethyl sulphoxide; EDTA: Ethylenediaminetetraacetic acid; FITC: Fluorescein isothiocyanate; fOPA: Flow opsonophagocytosis assay; FS: Forward scatter; HBSS: Hanks balanced salt solution; Hib: Haemophilus influenzae type B; IFNy: Interferon gamma; Ig: Immunoglobulin; KOPA: Killing opsonophagocytosis assay; LOS: Lipooligosaccharide; MFI: Mean fluorescence index; NAD: Nicotinamide adenine dinucleotide; NIS: Non-immune serum; NTHi: Nontypeable Haemophilus influenzae; OD: Optical density; OPA-BB: Opsonophagocytosis assay blocking buffer; PBS: Phosphate buffered saline; PHE: Public Health England; SBA: Serum bactericidal assay; sBHI: Supplemented brain heart infusion broth; SS: Side scatter

\section{Acknowledgments}

We would like to thank the laboratory staff at Public Health England, Porton Down for kindly contributing serum for use in the development of these assays.

\section{Funding}

Funding was received from UK Department of Health and grants from GlaxoSmithKline Biologicals SA. UK department of health had no role in the design of the study or the collection, analysis and interpretation of data. GlaxoSmithKline Biologicals played a role in project initiation and reviewed and approved the final manuscript. The views expressed in this publication are those of the authors and not necessarily those of Public Health England or the Department of Health.

\section{Availability of data and materials}

The data set supporting the conclusion of the current study is available upon request from the corresponding author.

\section{Trademark statement}

Synflorix is a trademark of the GSK group of companies.

\section{Authors' contributions}

SCT, AG, PL, DW initiated the study. PL, DW provided bacterial strains. TMAW and KJS provided sera, along with the corresponding ethics statement, and contributed input into experimental design and interpretation of data. SRT, SCT conceived and designed experiments. SRT performed experiments, analysed data, prepared tables and/or figures, wrote the paper. SL, KK performed experiments, analysed data. All authors had full access to the data, reviewed and approved the final manuscript before it was submitted by the corresponding author.

\section{Ethics approval and consent to participate}

All laboratory staff at Public Health England, Porton Down that donated blood signed an informed consent form. All samples were anonymised. The consent form used for the collection of blood, to be used as anonymised reagents or controls for assay development, did not require approval by an external ethics committee, which is in compliance with revised guidance Governance Arrangements for UK Research Ethics Committees (GAfREC) (September 2011). The blood collection consent form has been through internal review at Public Health England to ensure it is fully compliant with all current regulations including the NHS Research Governance Framework for Health and Social Care (April 2005), the World Medical Association Declaration of Helsinki (1996), the Human Tissue Act (2004) and the Data Protection Act (1998).

The study carried out at University Southampton Faculty of Medicine (ClinicalTrials.gov: NCT01701869) was performed in accordance with the Declaration of Helsinki and was approved by the National Research Ethics Service (NRES) Southampton B Committee (12/SC/0304). All subjects gave written informed consent.

\section{Consent for publication}

Not applicable.

\section{Competing interests}

All authors have declared the following interests: PL and DW are employees of the GSK group of companies. PL reports ownership of shares and/or restricted shares in the GSK group of companies. The other authors report no financial competing interests.

\section{Publisher's Note}

Springer Nature remains neutral with regard to jurisdictional claims in published maps and institutional affiliations.

\section{Author details}

${ }^{1}$ Public Health England, Microbiological Services, Porton Down, Salisbury SP4 OJG, UK. ${ }^{2}$ Clinical \& Experimental Sciences, University of Southampton Faculty of Medicine, Southampton General Hospital, Tremona Road, Southampton, UK. ${ }^{3} \mathrm{GSK}$, Rixensart, Belgium.

Received: 19 December 2017 Accepted: 11 October 2018

Published online: 29 October 2018

\section{References}

1. Foxwell AR, Kyd JM, Cripps AW. Nontypeable Haemophilus influenzae: pathogenesis and prevention. Microbiol Mol Biol Rev. 1998;62(2):294-308.

2. Holder RC, Kirse DJ, Evans AK, Peters TR, Poehling KA, Swords WE, et al. One third of middle ear effusions from children undergoing tympanostomy tube placement had multiple bacterial pathogens. BMC Pediatr. BioMed Central. 2012;12:87.

3. Faden H, Brodsky L, Bernstein J, Stanievich J, Krystofik D, Shuff C, et al. Otitis media in children: local immune response to nontypeable Haemophilus influenzae. Infect Immun. 1989;57(11):3555-9.

4. Murphy TF, Faden H, Bakaletz LO, Kyd JM, Forsgren A, Campos J, et al. Nontypeable Haemophilus influenzae as a pathogen in children. Pediatr Infect Dis J. 2009;28(1):43-8.

5. Moghaddam SJ, Ochoa CE, Sethi S, Dickey BF. Nontypeable Haemophilus influenzae in chronic obstructive pulmonary disease and lung cancer. Int J Chron Obstruct Pulmon Dis. 2011;6:113-23.

6. Cartwright S 2012. An evaluation of screening for COPD against the National Screening Committee criteria. <https://legacyscreening.phe.org.uk/ policydb_download.php?doc=360>. Accessed 15 Dec 2017.

7. Alikhan MM, FE-H L. Understanding nontypeable Haemophilus influenzae and chronic obstructive pulmonary disease. Curr Opin Pulm Med. 2014; 20(2):159-64.

8. Langereis JD, De Jonge MI. Invasive disease caused by nontypeable Haemophilus influenzae. Emerg Infect Dis. 2015;21(10):1711-8.

9. Murphy TF. Vaccines for nontypeable Haemophilus influenzae: the future is now. Clin Vaccine Immunol. 2015;22:459-66 American Society for Microbiology.

10. Poolman JT, Bakaletz L, Cripps A, Denoel PA, Forsgren A, Kyd J, et al. Developing a nontypeable Haemophilus influenzae (NTHi) vaccine. Vaccine. 2000;19(Suppl 1):S108-15.

11. Murphy TF. Vaccine development for non-typeable Haemophilus influenzae and Moraxella catarrhalis: progress and challenges. Expert Rev Vaccines. 2005;4(6):843-53.

12. Prymula R, Schuerman L. 10-valent pneumococcal nontypeable Haemophilus influenzae PD conjugate vaccine: Synflorix ${ }^{\mathrm{T}}$. Expert Rev Vaccines. 2009;8(11):1479-500.

13. Prymula R, Peeters P, Chrobok V, Kriz P, Novakova E, Kaliskova E, et al. Pneumococcal capsular polysaccharides conjugated to protein $D$ for prevention of acute otitis media caused by both Streptococcus pneumoniae 
and non-typable Haemophilus influenzae: a randomised double-blind efficacy study. Lancet. 2006:367(9512):740-8.

14. Schuerman L, Borys D, Hoet B, Forsgren A, Prymula R. Prevention of otitis media: now a reality? Vaccine. 2009;27(42):5748-54

15. Clarke C, Bakaletz LO, Ruiz-Guiñazú J, Borys D, Mrkvan T. Impact of protein D-containing pneumococcal conjugate vaccines on non-typeable Haemophilus influenzae acute otitis media and carriage. Expert Rev Vaccines. Taylor \& Francis. 2017;16(7):751-64.

16. Ercoli G, Baddal B, Alessandra G, Marchi S, Petracca R, Aricò B, et al. Development of a serological assay to predict antibody bactericidal activity against non-typeable Haemophilus influenzae. BMC Microbiol. 2015;15(1):87.

17. Jalalvand F, Littorin N, Su Y-C, Riesbeck K. Impact of immunization with Protein F on pulmonary clearance of nontypeable Haemophilus influenzae. Vaccine Elsevier Ltd. 2014;32(20):2261-4.

18. Townsend K, Ladhani SN, Findlow H, Borrow R. Evaluation and validation of a serum bactericidal antibody assay for Haemophilus influenzae type $b$ and the threshold of protection. Vaccine. Elsevier. 2014;32(43):5650-6.

19. Murphy TF, Bakaletz LO, Kyd JM, Watson B, Klein DL. Vaccines for otitis media: proposals for overcoming obstacles to progress. Vaccine. 2005; 23(21):2696-702.

20. Winokur PL, Chaloner K, Doern GV, Ferreira J, Apicella MA. Safety and immunological outcomes following human inoculation with nontypeable Haemophilus influenzae. J Infect Dis. Oxford University Press. 2013;208(5): 728-38.

21. Sabirov A, Casey JR, Murphy TF, Pichichero ME. Breast-feeding is associated with a reduced frequency of acute otitis media and high serum antibody levels against NTHi and outer membrane protein vaccine antigen candidate P6. Pediatr Res. NIH Public Access. 2009:66(5):565-70.

22. Faden H, Bernstein J, Brodsky L, Stanievich J, Krystofik D, Shuff C, et al. Otitis media in children. I. The systemic immune response to nontypable Hemophilus influenzae. J Infect Dis. 1989;160(6):999-1004.

23. Bernstein JM, Faden HS, Loos BG, Murphy TF, Ogra PL. Recurrent otitis media with non-typable Haemophilus influenzae: the role of serum bactericidal antibody. Int J Pediatr Otorhinolaryngol. 1992;23(1):1-13.

24. Brookes C, Kuisma E, Alexander F, Allen L, Tipton T, Ram S, et al. Development of a large scale human complement source for use in bacterial immunoassays. J Immunol Methods. Elsevier B.V. 2013;391(1-2):39-49.

25. Humphries HE, Brookes C, Allen L, Kuisma E, Gorringe A, Taylor S. Seroprevalence of antibody-mediated, complement-dependent opsonophagocytic activity against Neisseria meningitidis serogroup B in England. Clin Vaccine Immunol American Society for Microbiology (ASM). 2015;22(5):503-9.

26. Findlow J, Taylor S, Aase A, Horton R, Heyderman R, Southern J, et al. Comparison and correlation of Neisseria meningitidis serogroup $B$ immunologic assay results and human antibody responses following three doses of the Norwegian meningococcal outer membrane vesicle vaccine MenBvac. Infect Immun. 2006;74(8):4557-65.

27. Richardson MP, Ayliffe MJ, Helbert M, Davies EG. A simple flow cytometry assay using dihydrorhodamine for the measurement of the neutrophil respiratory burst in whole blood: comparison with the quantitative nitrobluetetrazolium test. J Immunol Methods. 1998;219(1-2):187-93.

28. Smith JA, Weidemann MJ. Further characterization of the neutrophil oxidative burst by flow cytometry. J Immunol Methods. 1993;162(2):261-8.

29. Rollins SA, Matis LA, Springhorn JP, Setter E, Wolff DW. Monoclonal antibodies directed against human C5 and C8 block complement-mediated damage of xenogeneic cells and organs. Transplantation. 1995;60(11):1284-92.

30. Martino A, Magagnoli C, De Conciliis G, D'Ascenzi S, Forster MJ, Allen L, et al. Structural characterisation, stability and antibody recognition of chimeric NHBA-GNA1030: an investigational vaccine component against Neisseria meningitidis. Vaccine. Elsevier Ltd. 2012;30(7):1330-42.

31. Rinder CS, Rinder HM, Smith BR, Fitch JCK, Smith MJ, Tracey JB, et al. Blockade of C5a and C5b-9 generation inhibits leukocyte and platelet activation during extracorporeal circulation. Clin Invest. 1995;96:1564-72.

32. Parker C. Eculizumab for paroxysmal nocturnal haemoglobinuria. Lancet. 2009;373(9665):759-67.

33. Klein JB, Scherzer JA, McLeish KR. Interferon-gamma enhances superoxide production by $\mathrm{HL}-60$ cells stimulated with multiple agonists. J Interf Res. 1991;11(2):69-74.

34. Marchi LF, Sesti-Costa R, Ignacchiti MDC, Chedraoui-Silva S, Mantovani B. In vitro activation of mouse neutrophils by recombinant human interferon-gamma: increased phagocytosis and release of reactive oxygen species and pro-inflammatory cytokines. Int Immunopharmacol. Elsevier B.V. 2014;18(2):228-35.

35. Nilsson UR, Nilsson B. Simplified assays of hemolytic activity of the classical and alternative complement pathways. J Immunol Methods. 1984;72:49-59.

36. Hallström T, Resman F, Ristovski M, Riesbeck K. Binding of complement regulators to invasive nontypeable Haemophilus influenzae isolates is not increased compared to nasopharyngeal isolates, but serum resistance is linked to disease severity. J Clin Microbiol. 2010;48(3):921-7.

37. Langereis JD, Stol K, Schweda EK, Twelkmeyer B, Bootsma HJ, de Vries SPW, et al. Modified lipooligosaccharide structure protects nontypeable Haemophilus influenzae from IgM-mediated complement killing in experimental otitis media. MBio. 2012;3(4):e00079-12.

38. Lichtenegger S, Bina I, Durakovic S, Glaser P, Tutz S, Schild S, et al. Serum resistance and phase variation of a nasopharyngeal non-typeable Haemophilus influenzae isolate. Int J Med Microbiol. 2017;307(2):139-46.

39. Langereis JD, de Jonge MI, Weiser JN. Binding of human factor $\mathrm{H}$ to outer membrane protein P5 of non-typeable Haemophilus influenzae contributes to complement resistance. Mol Microbiol. 2014;94(1):89-106.

40. Santos GF, Deck RR, Donnelly J, Blackwelder W, Granoff DM. Importance of complement source in measuring meningococcal bactericidal titers. Clin Diagn Lab Immunol American Society for Microbiology (ASM). 2001;8(3):616-23.

41. Khan MN, Kaur R, Pichichero ME. Bactericidal antibody response against P6, protein D, and OMP26 of nontypeable Haemophilus influenzae after acute otitis media in otitis-prone children. FEMS Immunol Med Microbiol. 2012; 65(3):439-47.

\section{Ready to submit your research? Choose BMC and benefit from:}

- fast, convenient online submission

- thorough peer review by experienced researchers in your field

- rapid publication on acceptance

- support for research data, including large and complex data types

- gold Open Access which fosters wider collaboration and increased citations

- maximum visibility for your research: over $100 \mathrm{M}$ website views per year

At BMC, research is always in progress.

Learn more biomedcentral.com/submissions 